Loma Linda University

TheScholarsRepository@LLU: Digital Archive of Research, Scholarship \& Creative Works

Loma Linda University Research Reports

$6-2020$

\title{
The Effects, Perceptions, and Attitudes of Previously Sedentary Individuals Starting an Exercise Program
}

Arlene Moreno

armoreno@llu.edu

Megan Rasmussen

Follow this and additional works at: https://scholarsrepository.llu.edu/rr

Part of the Dietetics and Clinical Nutrition Commons, and the Exercise Physiology Commons

\section{Recommended Citation}

Moreno, Arlene and Rasmussen, Megan, "The Effects, Perceptions, and Attitudes of Previously Sedentary Individuals Starting an Exercise Program" (2020). Loma Linda University Research Reports. 35.

https://scholarsrepository.llu.edu/rr/35

This Research Report is brought to you for free and open access by TheScholarsRepository@LLU: Digital Archive of Research, Scholarship \& Creative Works. It has been accepted for inclusion in Loma Linda University Research Reports by an authorized administrator of TheScholarsRepository@LLU: Digital Archive of Research, Scholarship \& Creative Works. For more information, please contact scholarsrepository@llu.edu. 


\title{
LOMA LINDA UNIVERSITY
}

School of Allied Health Professions

Department of Nutrition and Dietetics

THE EFFECTS, PERCEPTIONS, AND ATTITUDES OF PREVIOUSLY SEDENTARY INDIVIDUALS STARTING AN EXERCISE PROGRAM

\author{
By \\ Arlene Moreno \\ Megan Rasmussen \\ JeJe Noval \\ Gurinder Bains \\ Lida Gharibvand \\ Edward Bitok \\ Heather Javaherian-Dysinger
}

June 2020 


\begin{abstract}
Background: Many Americans do not eat healthfully or exercise, which is associated with higher risk of disease. Nutrition and exercise awareness have increased, but people experience barriers preventing lifestyle change. ${ }^{4}$ Limited research has been completed on the impact of nutrition education on dietary intake.
\end{abstract}

Objective: Examine whether starting an exercise program with or without nutrition education can influence dietary choices in previously sedentary individuals, and to determine their perceptions and attitudes.

Design: Mixed methods study gathering quantitative data through a food frequency questionnaire, InBody test, and demographics/exercise activity survey. Qualitative data was gathered through focus groups. Participants completed six weeks of exercise.

Participants: Male or female between 20 and 50 years who had been previously sedentary for at least 6 months but had started exercising between one week and three months. They had to be able to perform moderate intensity exercise at least two days per week for thirty minutes. Participants were excluded if they were pregnant (self-reported) or injured to prevent exercise. Six participants completed the study, with four participating in focus groups. Intervention: Group A received nutrition education. Group B did not. Main outcomes: Food choices, weight, lean body mass, body fat percentage, visceral fat, and perceptions on diet and exercise.

Statistical Analyses Performed: The Linear Mix Model was used for InBody data. Independent ttest was used for food frequency data. Dedoose and Otter were used for qualitative data. 
Results: Group A significantly decreased in weight and reported eating significantly less sweets than Group B during the final assessment. Three themes emerged: Professional help, selfefficacy, and the power of habits.

Conclusions: Individuals will encounter ambivalence regardless of what stage of change they are in. Nutrition counseling can guide clients to proceed with change. Not everyone will consider changing dietary habits after starting to exercise regardless of nutrition education.

\section{INTRODUCTION}

In America today, individuals are not getting the proper exercise and nutrition they need. ${ }^{1}$ Across the nation, many individuals sit in cars driving to their jobs to work at desks all day and lounge on the couch after returning home. Many buy fast food for breakfast, lunch, and dinner because there is no time for shopping or cooking. With the stress of getting ahead in their jobs, many Americans put thoughts of exercise and healthy eating to the back of their minds. According to the Center for Disease Control and Prevention's (CDC) National Health Statistics Report, about 23\% of Americans met the recommendations for physical activity between 2010 and 2015. ${ }^{1}$ This means that $77 \%$ of Americans did not meet those physical activity recommendations. These recommendations include at least 150 minutes of moderate aerobic exercise or 75 minutes of vigorous aerobic exercise per week. ${ }^{2}$ The CDC also recommends at least two days of strength training each week. ${ }^{2}$ The Standard American Diet (SAD) includes an abundance of refined grains, red meats, fried foods, desserts, and sugary beverages. ${ }^{3}$ In general, Americans of all ages are not eating a healthy diet or exercising. These practices are associated with higher risk of developing diseases such as obesity, cardiovascular disease, and diabetes. ${ }^{3}$ 
Many more people are becoming aware of their need to live healthier lives. According to the National Health and Nutrition Examination Survey 2013-2016, almost half of Americans have tried to lose weight within one year. Many individuals seek popular weight loss method information from the media. ${ }^{4}$ One of the most popular weight-control methods people turn to is fad diets. These usually include restricting one or more of the macronutrients (carbohydrates, proteins, and fats). ${ }^{5}$ For example, the currently popular ketogenic diet extremely limits carbohydrates and increases fat. ${ }^{6}$ Other methods reported include exercising, fasting, eating less food/calories, eating more fruits and vegetables, and drinking lots of water. ${ }^{4}$ However, many people still complain of gaining the weight after they have lost weight. ${ }^{5}$

Although individuals are becoming aware of their need to live healthier lives, many face barriers that prevent them from eating healthfully and exercising. These barriers to exercise and healthy eating impact a wide range of people with various health conditions. Some of the most common barriers to exercise in a population of obese type 2 diabetes patients included lack of time, boredom with exercise, physical discomfort in exercising, and being too tired. ${ }^{7}$ For a group of osteopenia and osteoporosis patients, barriers to exercise included lack of time or transportation, lack of interest, and fear of injury. ${ }^{8}$ In a group of adolescent and young adult cancer survivors, the most common barriers to exercise and healthy diet included lack of resources, negative thoughts and feelings, and negative social and environmental influences. ${ }^{9}$

A few studies in the current body of literature have examined the effects of exercise on diet choices. Rocha et al (2016) examined the effects of a 12-week aerobic exercise program on eating behavior, food cravings, and 7-day energy intake in inactive men. ${ }^{10}$ The study concluded that 12 weeks of moderate-intensity aerobic exercise decreased food cravings and increased the conscious restriction of food to control body mass. ${ }^{10}$ Joo et al (2019) examined the effects of a 
15-week aerobic exercise program on dietary patterns in young adults. ${ }^{11}$ This study found that 15 weeks of aerobic exercise motivated young adults to make healthier diet choices. ${ }^{11}$ While both studies showed there may be a correlation between starting an exercise program and changing dietary habits, neither had a control group. This makes it harder to confirm that exercise alone motivated the changes in dietary habits.

Limited research has been completed on the impact of nutrition education as an intervention impacting dietary intake. Vasconcelos et al (2019) completed a community-based food education program on nutrition-related knowledge. Although the program positively impacted nutrition-related knowledge, the participants recruited were middle-aged and elderly patients with type 2 diabetes from a primary health care facility, which is a very specific population. ${ }^{12}$ Sharma et al (2019) conducted a nutrition education intervention on information technology (IT) professionals. After the nutrition education was given, there were significant improvements in their nutritional knowledge. ${ }^{13}$ Both studies were done on very specific populations, and neither were completed with an exercise program, making it hard to conclude that nutrition education is an effective intervention for changing dietary habits.

There are two theories that were used to support the qualitative portion of our proposed research study—the transtheoretical model of behavior change and the health belief model. According to Prochaska \& Velicer, the transtheoretical model proposes that there are six stages involved in making a behavior change: precontemplation, contemplation, preparation, action, maintenance, and termination. ${ }^{14}$ This model is based on the idea that people do not make behavior changes quickly, and that they move through a continuous cycle. ${ }^{15}$ The health belief model, developed by Rosenstock, Hochbaum, Kegeles, and Leventhal, discusses the theory of motivation needed for an individual to adopt a preventive health behavior change. ${ }^{16}$ Based on 
this model, the following ideas influence an individual's likelihood of making a behavior change: perceived susceptibility, severity, benefits, and barriers, cue to action, and self-efficacy. Perceived susceptibility and severity refer to whether a person feels vulnerable to the disease and whether they feel contracting the disease would be serious. ${ }^{16}$ Perceived benefits and barriers refer to whether the person feels making a change would be beneficial and if there will be obstacles. Cue to action refers to the trigger for making the behavior change, and self-efficacy refers to the confidence a person has in their ability to make a behavior change. ${ }^{16,17}$ Overall, within the qualitative portion of our study, we want to examine what motivates people to implement a behavior change and compare our answers within these two models.

The problem this study addresses is the lack of information on how the transtheoretical model of behavior change and the health belief model illuminate the impact of exercise on dietary habits with or without nutrition education. Therefore, the purpose of our graduate student research study is to examine whether starting an exercise program with or without nutrition education can influence dietary choices in previously sedentary individuals, and to determine their perceptions and attitudes.

\section{SUBJECTS}

A total of 10 participants were assessed at baseline. Six participants completed this study. Each participant was randomized into one of two groups, Group A or Group B. Group A was the experimental group that received nutrition education. Group B was the control group that did not receive nutrition education. Participants were randomized into groups ahead of time by blindly selecting a piece of paper from an envelope with either Group A or Group B written on it and recording it for subjects 1-40. Because the goal of the study was to see if nutrition education would affect dietary choices, we did not want to lead any of the participants in Group B to think 
about nutrition. To accomplish this, we did not tell Group B that Group A would receive nutrition education. After the study was completed, Group B was informed that Group A received education. We also gave Group B the educational handout at that time. There was one separate informed consent document for each group.

Recruitment of subjects was completed through flyers posted around LLU campus and the surrounding communities, LLUH email, word of mouth, LLUH social media, and advertisement through Drayson Center fitness classes.

Inclusion Criteria: Men and women between 20 and 50 years who have been previously sedentary for at least 6 months but have been exercising between one week and three months. They must be able to perform moderate intensity exercise at least two days per week in at least 30-minute sessions.

Exclusion Criteria: Pregnant women (self-reported) and those who are currently injured to prevent them from exercising.

All methods and procedures were approved by the Loma Linda University Institutional Review Board.

\section{METHODS}

\section{InBody Testing}

Body composition was tested using the InBody 770 . This assessed the participants' lean body mass, fat mass, water weight, visceral fat, and BMI. This test took less than 5 minutes to complete for each participant. The InBody 770 calculates the measured data using bioelectrical impedance. The testing was done in the morning around the same time for each participant. They were asked to refrain from eating or drinking that morning to be able to get the most accurate reading. 


\section{Demographics, Activity, and Food Frequency Questionnaire}

An electronic questionnaire was given to each participant through Qualtrics. The questionnaire consisted of demographic, physical activity, and food frequency questions. The demographic questions included participant’s age, gender, ethnicity, education level, and occupation. The physical activity questions asked for their current physical activity level including type, duration, and intensity. The food frequency questions were used to obtain data on what each participant was eating before, at mid-way point during the study, and after the study. These food frequency questions were developed by the Nutrition Research Group in the Loma Linda University School of Public Health. There are twelve sections to complete, including but not limited to, breads, starches and grains, vegetables, fruits, eggs and dairy, and fats and oils. The entire questionnaire took approximately 40 minutes to complete.

\section{Focus Group Questions}

For the qualitative portion of the study, four participants were recruited to participate in a focus group at the beginning and at the end of the study. We solicited volunteers for those interviews during the first visit. Three volunteers were from Group A, and one volunteer was from group B. These interviews helped us. We asked open-ended questions about their thoughts and perceptions on exercise, nutrition knowledge, their health, and nutrition history. The purpose of these interviews was to dig deeper into peoples’ perceptions and attitudes about exercise and nutrition. Both participants' perceptions of diet changes and their food frequency questionnaire results helped us understand how exercise influences the diet. These interviews were audio recorded and transcribed. The recordings will either be destroyed at the end of the study.

\section{Exercise program}


Each week, the participants were required to complete at least 150 mins of moderate-intensity exercise. According to the American College of Sports Medicine (ACSM), moderate intensity exercise is defined as anything that raises the heart rate above resting or working at approximately three to six metabolic equivalents (METs). ${ }^{18}$ Examples include walking briskly or playing doubles tennis. Vigorous intensity aerobic exercise is defined as working at least six METs. ${ }^{18}$ Examples include jogging or participating in a strenuous fitness class. Each exercise session was required to last at least 30 minutes. ${ }^{18}$

\section{Compliance Log}

To ensure the participants followed the exercise program guidelines, they each filled out an exercise compliance log for every week of the study. This included the type of exercise they performed, the duration of the exercise, and the intensity level. Participants who failed to complete their required exercise for more than one week were dismissed from the study.

\section{Nutrition Education}

Group A received nutrition education once at the beginning of the second week of the study. This consisted of a 30-minute interactive lecture and a 15-minute question-and-answer session. The information covered was basic nutrition principles for good health and to support regular exercise.

\section{Statistical Analysis}

For the quantitative data, the Linear Mix Model was used to analyze our InBody test data and the independent t-test was used to analyze our food frequency questionnaire data.

\section{Qualitative Analysis}

For the qualitative data, Otter was used to transcribe and Dedoose was used to create themes.

\section{PROCEDURES}


The duration of this study was seven weeks. Each participant was randomized ahead of time into one of two groups, Group A or Group B. Additionally, four volunteers were recruited to participate in focus groups. Table 1 outlines the required visits for each group and what took place during each visit. We met with participants in Group A four to six times and participants in Group B, three to five times depending on their additional participation in the focus groups. The initial visit consisted of collecting baseline information, the second visit consisted of a mid-study assessment, and the final visit was the final assessment. For each week of the seven-week study, participants were required to complete a minimum of 150 minutes of moderate-intensity exercise. Each exercise session was required to be at least 30 minutes long and spread throughout the week. After each exercise session, participants filled out an exercise compliance log. Additionally, the participants received emails to remind them to complete their exercise for the week.

Table 1: Study Protocol by Group Over Time $(n=6)$

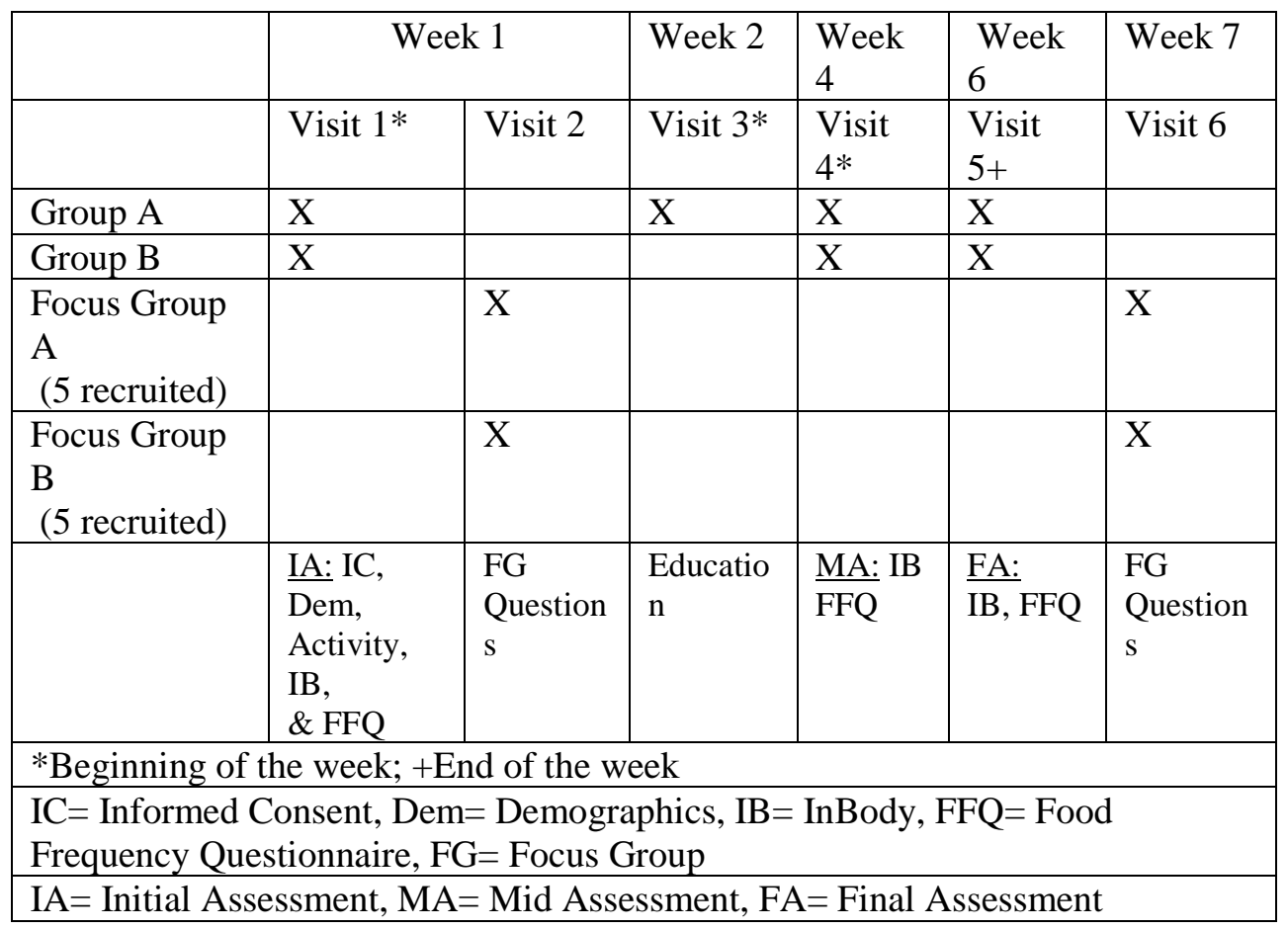




\section{RESULTS}

A total of 10 participants were assessed at baseline. One participant decided to discontinue the study after the nutrition education meeting reminder email was sent out. Another participant did not reply after the initial assessment for nutrition education or follow up assessments (Table 1). A third participant did not exercise enough one week and missed another week of exercising and chose to leave the study before the mid-assessment. A fourth participant was unable to meet for the mid-assessment and did not reply after another assessment time and day was set. This volunteer was from Group B focus group and did not participate in the final focus group (Table 1). Six participants completed the study (Table 2).

\section{Quantitative}

Two data sets were examined: food frequency questionnaire and InBody test.

Demographics and activity frequency, duration, and intensity were also recorded (Table 2; Table 3). Most of our participants were Loma Linda students (Table 2).

Table 2. Demographic Characteristics of Participants by Group $(n=6)$

\begin{tabular}{|c|c|c|c|c|}
\hline & Answers & $\begin{array}{c}\text { Group } \\
\text { A } \\
\end{array}$ & $\begin{array}{c}\text { Group } \\
\text { B } \\
\end{array}$ & Total \\
\hline \multirow[t]{2}{*}{ Gender } & Male & 2 & 0 & 2 \\
\hline & Female & 1 & 3 & 4 \\
\hline \multirow{3}{*}{ Ethnicity } & White & 2 & 0 & 2 \\
\hline & Asian & 1 & 2 & 3 \\
\hline & Unknown & 0 & 1 & 1 \\
\hline Age & $22-29$ & & & 6 \\
\hline \multirow{2}{*}{$\begin{array}{c}\text { Marital } \\
\text { Status }\end{array}$} & Single & 2 & 3 & 5 \\
\hline & Married & 1 & 0 & 1 \\
\hline \multirow{3}{*}{ Education } & $\leq$ Highschool & 1 & 0 & 1 \\
\hline & Bachelor's Degree & 1 & 2 & 3 \\
\hline & $\geq$ Graduate Degree & 1 & 1 & 2 \\
\hline \multirow{3}{*}{ Occupation } & Student & 3 & 1 & 4 \\
\hline & LLU employee: PPDPT-66 & 0 & 1 & 1 \\
\hline & Other: Payroll Representative & 0 & 1 & 1 \\
\hline
\end{tabular}


The majority (67\%) of the participants had been exercising for one month at least two days a week in 30-minute sessions (Table 3).

Table 3. Baseline Exercise Characteristics by Group ( $n=6)$

\begin{tabular}{|c|c|c|c|c|}
\hline $\begin{array}{l}\text { Exercise } \\
\text { Routine }\end{array}$ & Answers & $\begin{array}{l}\text { Group } \\
\text { A }\end{array}$ & $\begin{array}{l}\text { Group } \\
\text { B }\end{array}$ & \begin{tabular}{|l} 
Tota \\
1
\end{tabular} \\
\hline \multirow{3}{*}{ Length } & $<1$ month & 0 & 1 & 1 \\
\hline & 1 month & 2 & 2 & 4 \\
\hline & 3 months & 1 & 0 & 1 \\
\hline \multirow{3}{*}{ Days/week } & $\leq 2$ days & 1 & 2 & 3 \\
\hline & 4 days & 2 & 0 & 2 \\
\hline & $\geq 5$ days & 0 & 1 & 1 \\
\hline \multirow{3}{*}{ Duration } & $15-30$ mins & 0 & 1 & 1 \\
\hline & 30-45 mins & 3 & 1 & 4 \\
\hline & 1 hour & 0 & 2 & 2 \\
\hline \multirow{3}{*}{ Type } & Aerobic & 0 & 0 & 0 \\
\hline & Strength & 1 & 0 & 1 \\
\hline & Combination of both & 2 & 3 & 5 \\
\hline \multirow[t]{4}{*}{ Intensity } & Low & 0 & 1 & 1 \\
\hline & Moderate & 2 & 2 & 4 \\
\hline & Vigorous & 0 & 0 & 0 \\
\hline & Combination of moderate to vigorous & 1 & 0 & 1 \\
\hline
\end{tabular}

\section{$\underline{\text { InBody Test Analysis }}$}

The results from the InBody analyses, for weight, Group A decreased, and Group B stayed approximately the same (Figure 1). The statistical analysis showed that the difference in weight between Group A and Group B was statistically significant upon final assessment (pvalue $=0.028$ ). Comparing all three assessments in Group A and Group B, Group A had higher lean body mass, lower visceral fat, and lower body fat than Group B, but these results were not statistically significant (Figure 1). 


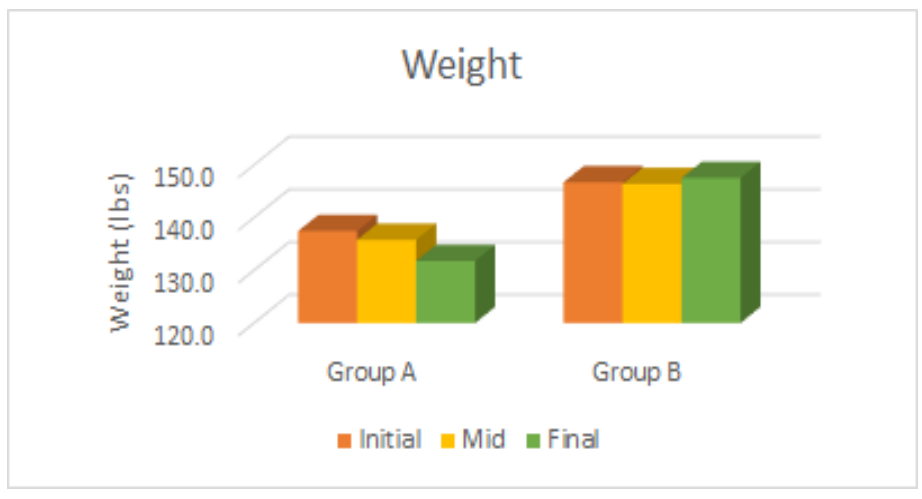

A

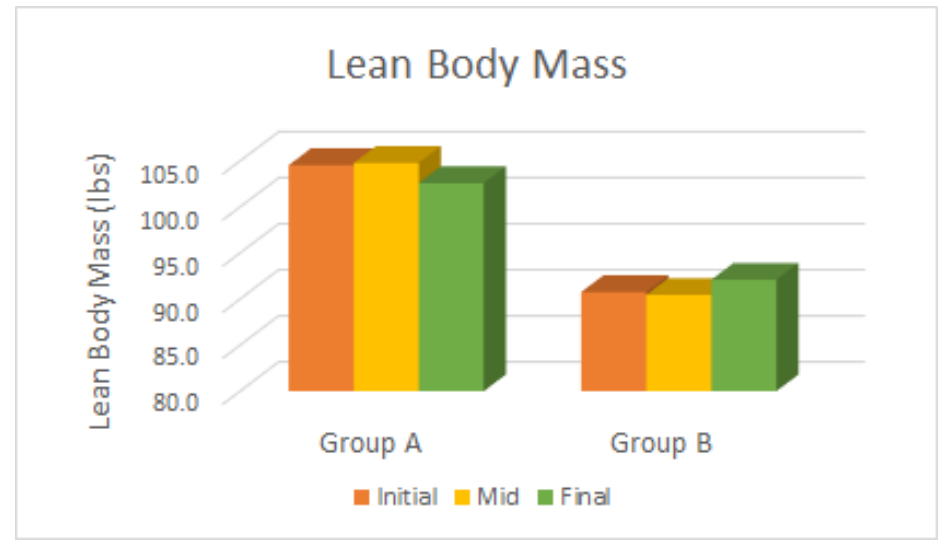

B

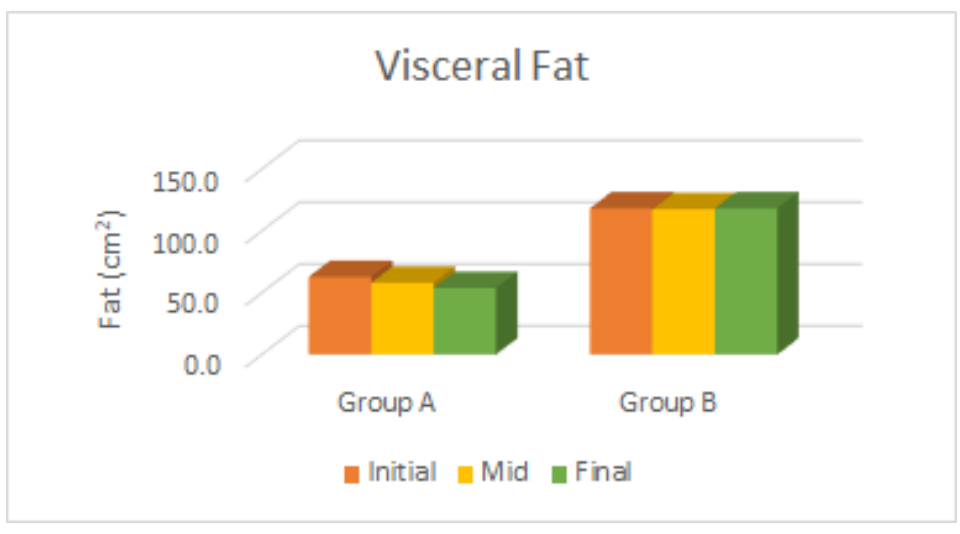

C 


\section{Body Fat}

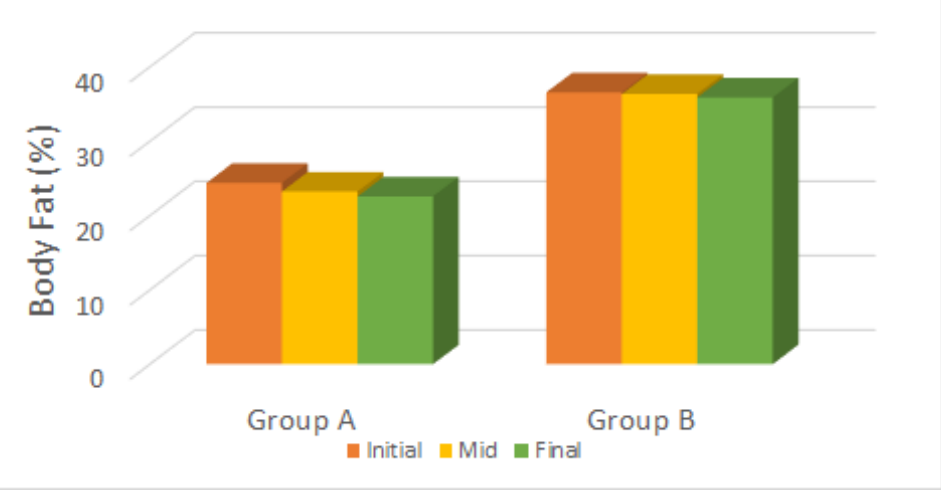

D

Figure 1. (A-D) InBody Measurement Changes Over Time by Group

Table 4. (A-B) Between Group InBody Assessment Over Time

A

\begin{tabular}{|l|l|l|l|l|l|l|}
\hline & \multicolumn{3}{|c|}{ Weight (lbs) } & \multicolumn{3}{c|}{ Body Fat \% } \\
\hline & Group A & Goup B & p-value & Group A & Group B & p-value \\
\hline Baseline & 137.5 & 146.9 & 0.719 & 24.4 & 36.6 & 0.123 \\
\hline Midway & 135.8 & 146.4 & 0.662 & 23.2 & 36.4 & 0.372 \\
\hline Final & 131.8 & 147.5 & 0.023 & 22.6 & 35.9 & 0.285 \\
\hline
\end{tabular}

B

\begin{tabular}{|l|l|l|l|l|l|l|}
\hline & \multicolumn{3}{|c|}{ Lean Body Mass (lbs) } & \multicolumn{3}{c|}{ Visceral Fat (cm $\left.{ }^{2}\right)$} \\
\hline & Group A & Goup B & p-value & Group A & Group B & p-value \\
\hline Baseline & 104.6 & 90.8 & 0.385 & 62.8 & 118.2 & 0.254 \\
\hline Midway & 104.8 & 90.5 & 0.777 & 58.0 & 117.6 & 0.361 \\
\hline Final & 102.6 & 92.1 & 0.227 & 53.7 & 118.2 & 0.062 \\
\hline
\end{tabular}

Table 5. (A-B) Mean Overall InBody Assessment Over Time $(n=6)$

A

\begin{tabular}{|c|c|l|c|l|l|l|l|l|l|}
\hline \multicolumn{3}{|c|}{ Weight (lbs) } & \multicolumn{2}{c|}{ p-value } & \multicolumn{3}{c|}{ Body Fat \% } & \multicolumn{2}{c|}{ p-value } \\
\hline $1^{\text {st }}$ & $2^{\text {nd }}$ & $3^{\text {rd }}$ & $1^{\text {st }}-2^{\text {nd }}$ & $1^{\text {st }}-3^{\text {rd }}$ & 1 st & $2^{\text {nd }}$ & $3^{\text {rd }}$ & $1^{\text {st }}-2^{\text {nd }}$ & $1^{\text {st }}-3^{\text {rd }}$ \\
\hline 142.2 & $\begin{array}{c}141 . \\
1\end{array}$ & 139.7 & 0.369 & 0.008 & 30.5 & 29.8 & 29.2 & 0.140 & 0.029 \\
\hline
\end{tabular}


B

\begin{tabular}{|c|c|c|c|c|c|c|c|c|c|}
\hline \multicolumn{3}{|c|}{ Lean Body Mass (lbs) } & \multicolumn{2}{|c|}{ p-value } & \multicolumn{3}{|c|}{ Visceral Fat $\left(\mathrm{cm}^{2}\right)$} & \multicolumn{2}{|c|}{ p-value } \\
\hline $1^{\mathrm{st}}$ & $2^{\text {nd }}$ & $3^{\text {rd }}$ & $1^{\text {st }}-2^{\text {nd }}$ & $1^{\text {st }}-3^{\text {rd }}$ & $1 \mathrm{st}$ & $2^{\text {nd }}$ & $3^{\text {rd }}$ & $1^{\text {st }}-2^{\text {nd }}$ & $1^{\text {st }}-3^{\text {rd }}$ \\
\hline 97.7 & 97.6 & 97.4 & 0.861 & 0.305 & 90.5 & 87.8 & 0.153 & 0.153 & 0.013 \\
\hline
\end{tabular}

$\underline{\text { Food Frequency Questionnaire Analysis }}$

Table 6. Mean intake of food groups for Group A and B upon final food frequency questionnaire assessment.

\begin{tabular}{|l|l|r|r|r|}
\hline \multicolumn{1}{|c|}{$\begin{array}{c}\text { Group } \\
\text { Statistics }\end{array}$} & & & & $\begin{array}{c}\text { Difference } \\
\text { between A \& B }\end{array}$ \\
\hline Grains & Group & N & Mean intake/svg & p-value \\
\hline & A & 3 & 2.5500 & 0.798 \\
\hline Vegetables & B & 3 & 2.4867 & \\
\hline & A & 3 & 3.6633 & 0.482 \\
\hline Fruits & B & 3 & 2.3233 & \\
\hline & $\mathrm{A}$ & 3 & 1.5733 & 0.450 \\
\hline Dairy & $\mathrm{B}$ & 3 & .9367 & \\
\hline & $\mathrm{A}$ & 3 & .7267 & 0.921 \\
\hline Protein & $\mathrm{B}$ & 3 & .6967 & \\
\hline & $\mathrm{A}$ & 3 & 3.2300 & 0.817 \\
\hline Sweets & $\mathrm{B}$ & 3 & 2.7967 & \\
\hline & $\mathrm{A}$ & 3 & .4667 & 0.049 \\
\hline & $\mathrm{B}$ & 3 & 1.1567 & \\
\hline
\end{tabular}

Out of all the food groups, there was a statistically significant difference in the 'Sweets' category. Sweets intake decreased over time in Group A (p-value $=0.049)$ and remained relatively the same for Group B. 


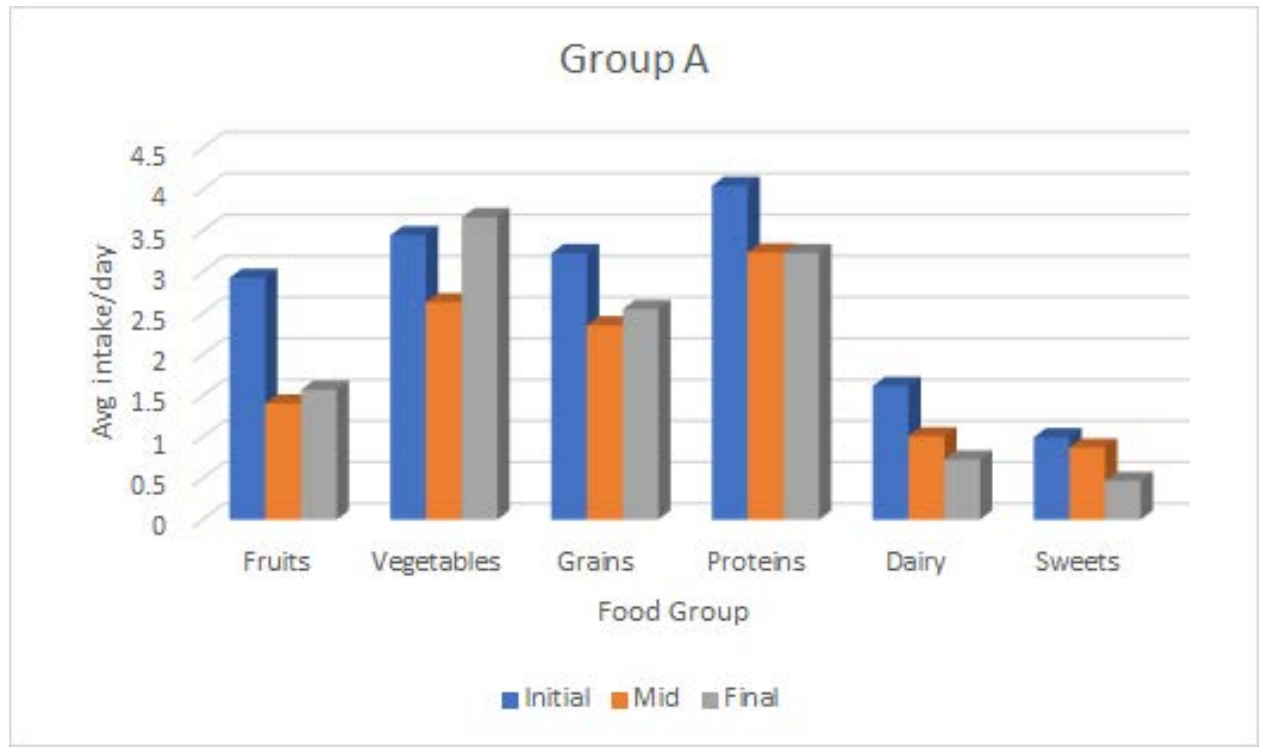

A

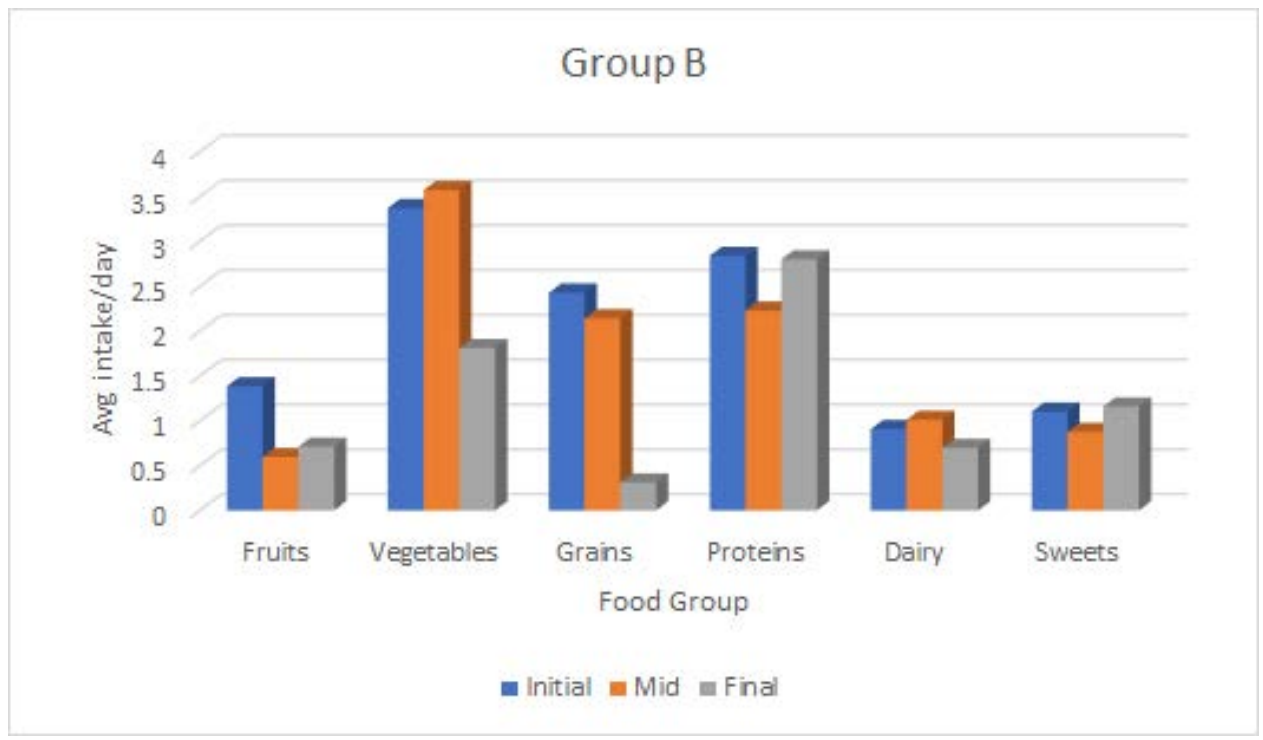

B

Figure 2. (A-B) Food Frequency Changes Over Time by Group

\section{Qualitative}

The purpose of the qualitative portion of this study was to determine participants' thoughts and attitudes surrounding exercise and nutrition before and after completing the 
exercise program. Four subjects volunteered to participate in the focus groups. One of these four subjects dropped out of the study before the final focus group was conducted. Each focus group was transcribed using Otter.ai. The transcriptions were coded, and categories and themes were created using Dedoose.

During our initial focus group, we asked the following questions: "What are your thoughts on exercise?”, What are some barriers that keep you from exercising?”, and "What keeps you motivated to keep exercising?”. During our final focus group, we asked the following questions: “Have you struggled with maintaining exercise?”, "How does it make you feel about yourself when you have consistently exercised?" and "What helps you to stay motivated to exercise?” We also asked participants from Group A to give feedback on the nutrition education session.

The following 3 themes came out of the qualitative data analysis: Professional Help, SelfEfficacy, and The Power of Habits. The theme of professional help originated from the following responses: "There's a ton of information on what you should be doing out there", "I discovered an app on my phone. It does all the thinking for me”, and "Finally, I can work out and have a clear goal in mind”.

Responses that led us to the theme of Self-efficacy include: "It helps to see improvement”, "Satisfied that I've done what I needed to do.", and "this is where I'm supposed to be.”

Responses that led to the theme of The Power of Habits include: "I am hoping to form a habit that I can keep when I get really busy again”, “It’s definitely easier to do once you force yourself to do it more often", and "If you just keep doing it even though it's not a lot at first that will get better over time.” 


\section{DISCUSSION}

The purpose of this study was to examine whether starting an exercise program with or without nutrition education can influence dietary choices in previously sedentary individuals, and to determine their perceptions and attitudes. In the quantitative data, two main results were found. The first result was that weight significantly decreased for Group A over time. In contrast, the weight of Group B increased upon final assessment. The second result was the intake from the category of sweets from the food frequency questionnaire, significantly decreased for Group A. For Group B, the intake of sweets slightly increased.

These results could have been related to the fact that Group A received nutrition education and Group B did not. This reflects on the qualitative themes. For Theme 1: Professional Help, receiving nutrition education from professionals could have influenced the participants in Group A to be more conscious about their food choices, ultimately decreasing their intake of sweets, and possibly leading to weight loss. Without having received nutrition education, the participants in Group B were not guided towards making dietary choices to promote weight loss. For Theme 2: Self-Efficacy, because Group A was more informed on basic nutrition principles, they were more confident in their ability to make a change. Group B may not have been as confident in their ability to make a change and could have resorted to eating more sweets as a comfort food. For Theme 3: Habits, because Group A was more confident, they were likely to be more consistent, which led to the formation of habits. Because Group B was less confident, they were less likely to move into the maintenance stage.

The results also reflect on the Transtheoretical Model of Behavior Change and the Health Belief Model. Although participants in Group B were in the action stage of exercising, they may have still been in the precontemplation stage of the transtheoretical model for making a change 
in food choices. Exercising may not always lead to weight loss without a subsequent change in dietary habits. Additionally, because these participants were in precontemplation, they were not aware of their need to make a change in dietary habits. Therefore, they had not yet weighed the benefits and barriers of change, which is the main concept of the Health Belief Model.

Previous literature has shown starting an exercise program to influence dietary choices by increasing conscious restriction of food, decreasing food cravings, and making healthier diet choices. ${ }^{10,11}$ These findings oppose our results because only the nutrition education group changed their dietary habits after exercising. Group B did not significantly change their dietary patterns, which suggests that exercise may not necessarily trigger people to change their dietary habits. Nutrition education may be the missing piece of the puzzle to create behavior change. However, this opposing finding could be a result of having a small sample size. A larger sample size would be warranted to confirm these findings. Further literature has shown that nutrition education improves nutrition knowledge. ${ }^{12,13}$ This aligns with our findings because the nutrition education group showed weight loss and decreased sweets intake. This indicates that nutrition education increased nutrition knowledge and enabled the participants to make better dietary choices.

\section{Strengths and Limitations}

One strength of this study was the collection of both qualitative and quantitative data. This provided the ability to triangulate data from InBody analysis, food frequency questionnaire, and focus groups. Another strength was the use of compliance logs. This helped to motivate participants to keep exercising and to ensure they were following through on the requirements. This study was not without limitations, however. One limitation was the small sample size and short duration. Small sample size makes it difficult to generalize results to the larger population 
and a short duration gives participants less time to adjust to exercising. One challenge with the duration is that multiple participants became sick during the study, which could have easily affected their dietary intake or ability to exercise. This study was also conducted in November and December. People often experience a shift in eating and exercise habits during these months due to the holidays. Additionally, all participants were students of Loma Linda University, which emphasizes which may have influenced our participants to be more health conscious. There could have also been recall bias when participants were filling out the food frequency questionnaire.

\section{CONCLUSIONS}

Ambivalence and barriers were encountered even though our participants were already in the action stage of exercising. Work and motivation are required to remain in action. Individuals starting an exercise program may not automatically think about changing their dietary habits, regardless of nutrition education. Nutrition counseling is a tool RDNs should use to guide clients in making and maintaining behavioral changes. Future studies should cover the effects of exercise on diet choices over a longer period of time or with those exercising for the first time. 


\section{References}

1. Grotto, D., \& Zied, E. (2010). The Standard American Diet and Its Relationship to the Health Status of Americans. Nutrition In Clinical Practice, 25(6), 603-612. doi: 10.1177/0884533610386234

2. Blackwell D, Clarke T. Cdc.gov. https://www.cdc.gov/nchs/data/nhsr/nhsr112.pdf. Published 2018. Accessed July 19, 2019.

3. Thalheimer J. Undoing the Unhealthful Western Diet: The typical American diet may be hazardous to your health. EN explores which dietary changes can have the biggest positive impact. 0-web.b.ebscohost.com.catalog.llu.edu. http://0web.b.ebscohost.com.catalog.llu.edu/ehost/detail/detail?vid=5\&sid=0c065395-b5184750-acef983c295aa7d9\%40sessionmgr102\&bdata=JnNpdGU9ZWhvc3QtbGl2ZSZzY29wZT1za XRl\#AN=128955370\&db=aph. Published 2019. Accessed July 19, 2019.

4. Martin C, Herrick K, Sarafrazi N, Ogden C. Attempts to Lose Weight Among Adults in the United States, 2013-2016. Cdc.gov.

https://www.cdc.gov/nchs/data/databriefs/db313.pdf. Published 2018. Accessed July 19, 2019.

5. Saltzman E, Thomason P, Roberts S. Fad Diets: A Review for the Primary Care Provider. 0-web.b.ebscohost.com.catalog.llu.edu. http://0web.b.ebscohost.com.catalog.llu.edu/ehost/detail/detail?vid=5\&sid=19d25fe6-404d409a-8366-fde5d29628a5\%40pdc-vsessmgr02\&bdata=JnNpdGU9ZWhvc3QtbGI2ZSZzY29wZT1zaXRl\#AN=5712212\&db =aph. Published 2001. Accessed July 18, 2019.

6. Mohorko N, Cernelic-Bizjak M, Poklar-Vatovec T et al. Weight loss, improved physical performance, cognitive function, eating behavior, and metabolic profile in a 12-week ketogenic diet in obese adults. 0-www-clinicalkey-com.catalog.llu.edu. https://0-wwwclinicalkey-com.catalog.llu.edu/\#!/content/medline/2-s2.0-30803508. Published 2019. Accessed July 26, 2019.

7. Egan A, Mahmood W, Fenton R et al. Barriers to exercise in obese patients with type 2 diabetes. 0-academic-oup-com.catalog.llu.edu. https://0-academic-oupcom.catalog.llu.edu/qjmed/article/106/7/635/1592102. Published 2013. Accessed July 26, 2019.

8. Rodrigues I, Armstrong J, Adachi J, MacDermid J. Facilitators and barriers to exercise adherence in patients with osteopenia and osteoporosis: a systematic review. 0-linkspringer-com.catalog.llu.edu. https://0-link-springercom.catalog.llu.edu/article/10.1007\%2Fs00198-016-3793-2. Published 2017. Accessed July 26, 2019. 
9. Wu Y, Yi J, McClellan J et al. Barriers and Facilitators of Healthy Diet and Exercise Among Adolescent and Young Adult Cancer Survivors: Implication for Behavioral Interventions. 0-web.a.ebscohost.com.catalog.llu.edu. http://0web.a.ebscohost.com.catalog.llu.edu/ehost/pdfviewer/pdfviewer?vid=20\&sid=6e112ac7354c-49b3-a036-0f507f2fc312\%40sessionmgr4007. Published 2015. Accessed July 26, 2019.

10. Rocha J, Paxman J, Dalton C, Winter E, Broom D. Login - University Libraries. ebscohost.com.catalog.llu.edu. http://0web.b.ebscohost.com.catalog.llu.edu/ehost/detail/detail?vid=7\&sid=b7d0bece-990142c1-b732-53fbe0de079d\%40pdc-vsessmgr03\&bdata=JnNpdGU9ZWhvc3QtbGl2ZSZzY29wZT1zaXRI\#AN=119278546\& $\mathrm{db}=$ aph. Published 2016. Accessed June 25, 2019.

11. Joo J, Williamson S, Vazquez A, Fernandez J, Bray M. The influence of 15-week exercise training on dietary patterns among young adults. www.nature.com. https://www.nature.com/articles/s41366-018-0299-3. Published 2019. Accessed May 14, 2019.

12. Vasconcelos C, Almeida A, Cabral M, Ramos E, Mendes R. The Impact of a Community-Based Food Education Program on Nutrition-Related Knowledge in MiddleAged and Older Patients with Type 2 Diabetes: Resul... - PubMed - NCBI. Ncbi.nlm.nih.gov. https://www.ncbi.nlm.nih.gov/pubmed/31284568. Published 2019. Accessed July 9, 2019.

13. Sharma P, Rani M. Effect of Digital Nutrition Education Intervention on the Nutritional Knowledge Levels of Information Technology Professionals. - PubMed - NCBI. Ncbi.nlm.nih.gov. https://www.ncbi.nlm.nih.gov/pubmed/27454492. Published 2019. Accessed July 9, 2019.

14. Prochaska J, Velicer W. The transtheoretical model of health behavior change. - PubMed - NCBI. Ncbi.nlm.nih.gov. https://www.ncbi.nlm.nih.gov/pubmed/10170434. Published 1997. Accessed July 10, 2019.

15. The Transtheoretical Model (Stages of Change). Sphweb.bumc.bu.edu. http://sphweb.bumc.bu.edu/otlt/MPHModules/SB/BehavioralChangeTheories/BehavioralChangeTheories6.html. Published 2018. Accessed July 10, 2019.

16. The Health Belief Model. Sphweb.bumc.bu.edu. http://sphweb.bumc.bu.edu/otlt/MPHModules/SB/BehavioralChangeTheories/BehavioralChangeTheories2.html. Published 2018. Accessed May 14, 2019.

17. What is Self-Efficacy Theory in Psychology? - PositivePsychology.com. PositivePsychology.com. https://positivepsychology.com/self-efficacy/. Published 2013. Accessed May 20, 2019.

18. Physical Activity guidelines for Americans 2nd edition. Health.gov. https://health.gov/paguidelines/secondedition/pdf/Physical_Activity_Guidelines_2nd_edition.pdf. Published 2018. Accessed July 18, 2019. 
Appendices

A. Compliance Log

\section{Activity Log}

ID\#

Week \#

\begin{tabular}{|c|l|l|}
\hline & Activity & Duration \\
\hline Day 1 & & \\
\hline Day 2 & & \\
\hline Day 3 & & \\
\hline Day 4 & & \\
\hline Day 5 & & \\
\hline & & Total minutes: \\
\hline
\end{tabular}

Moderate intensity exercise is anything that raises the heart rate above resting.

Examples of moderate intensity exercise include but not limited to:

Brisk walking

Doubles tennis

Raking the yard
Volleyball

Dancing

Bicycling/Cycling
Water aerobics

Gardening

Yoga 
*A minimum of 150 minutes of moderate exercise required each week. Must be spread out in at least $\underline{2 \text { days. }}$.

\section{B. Semi-structured Focus Group Questions}

Focus Group 1: Pre-intervention

Intro: "Hello. We would like to welcome you to our focus group. Thank you all so much for giving us your time. We truly appreciate it. We are excited to hear from you and learn from you all today! We would like you to feel as comfortable as possible. Just remember, there are no right or wrong answers and if you do not feel comfortable sharing, you do not have to."

- How would you describe the physical activity you are doing now?

o What type of exercise do you do?

o How often do you exercise?

o How long do you exercise each time?

0 At what intensity do you exercise?

- What are your thoughts on exercise?

0 What does exercise mean to you?

o Why do you exercise?

- What are some barriers that have kept you from exercising in the past?

- When did you start thinking about making a change in exercise?

o What was the reason you decided to change?

o Was there an event that sparked the change?

- What have you been doing to maintain this change?

0 For those who have been exercising longer (2-3 months), what motivates you to keep going?

o For those of you who just recently made this change, can you think about what might keep you going?

o What kind of support system do you have?

- If any, what other changes have you made since you have started exercising?

- (can be very vague ... any other changes you've made?)

- Sleep or taking less of an anti-inflammatory medication

- Maybe mislead them initially.... take their mind elsewhere

Focus Group 2: Post-intervention

Intro: "Hello everyone. Thank you all for joining us again for another focus group. We appreciate you taking your time to be here. It is very helpful to learn from you all. A quick reminder before we get started: there are no right or wrong answers and if you do not feel comfortable sharing, you don't have to." 
Group A (Education)

- What are your thoughts on exercise now?

0 Have your thoughts about exercise changed in the last 6 weeks?

o Why might your thoughts have changed?

- When you have consistently exercised, how does it make you feel about yourself?

- When you fail to exercise, how does it make you feel about yourself?

- Has anyone struggled with maintaining exercise?

o How does it make you feel?

- If any, what other health or lifestyle changes have you made in the last 6 weeks?

0 If any, what changes have you made regarding nutrition?

- How impactful was the nutrition education?

o Was the information useful?

0 On a scale of 1-5 (5 being very satisfied, and 1 being very dissatisfied) how satisfied were you with the nutrition education?

o What did you like about the nutrition education?

Group B (Non-education)

- What are your thoughts on exercise now?

o Have your thoughts about exercise changed in the last 6 weeks?

0 Why might your thoughts have changed?

- When you have consistently exercised, how does it make you feel about yourself?

- When you fail to exercise, how does it make you feel about yourself?

- Has anyone struggled with maintaining exercise?

o How does it make you feel?

- If any, what other health or lifestyle changes have you made in the last 6 weeks?

- If any, what changes have you made regarding nutrition? 
C. Nutrition Education Handout

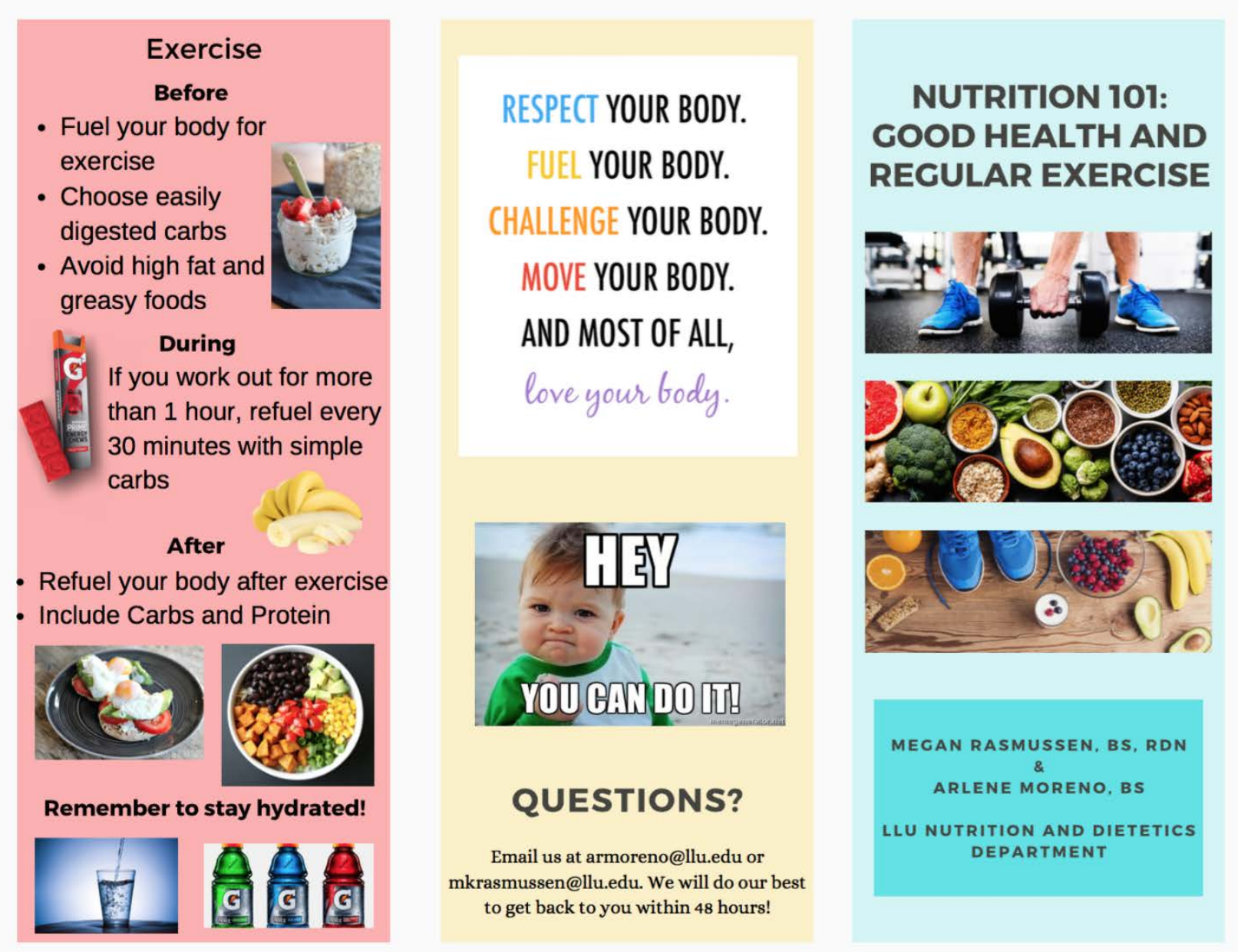




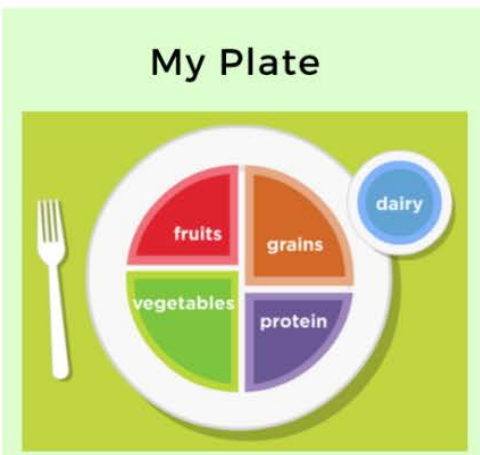

Building blocks for each meal

- Fruit: 3-4 svg/day

- Vegetables: 4-6 svg/day

- Grains: 5-8 svg/day

- Proteins: 3-6 svg/day

- Dairy 3-4 svg/day

Notes:

\section{Macronutrients}

Carbohydrates

- Function:

- Sources:

- $45-55 \%$ total Calories

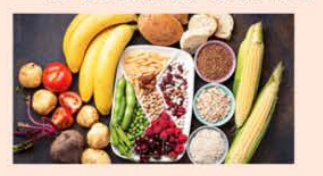

Fat

- Function:

- Sources:

- 20-35 \% total Calories

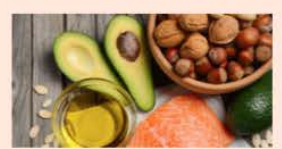

$$
\text { Protein }
$$

- Function:

- Sources:

- $10-35 \%$ total Calories

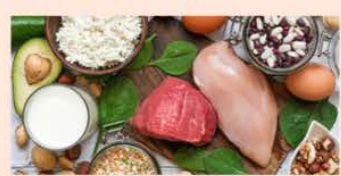

Nutrition Label

Nutrition Facts

8 servings per container

Serving size

Amount per $2 / 3$ cup

Calories

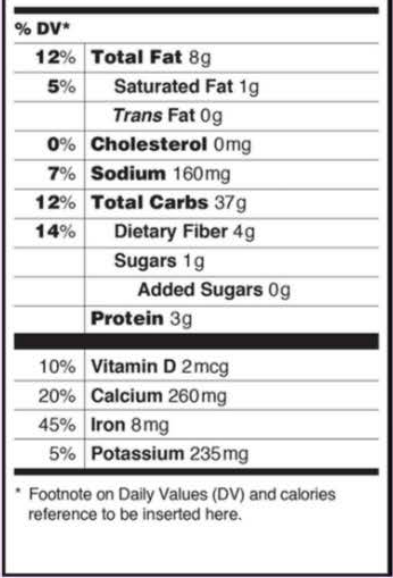

Make sure to check:

- Serving Sizes

- Cal per serving

- \% Daily Values

- Sodium content

- Sugar content

- Saturated fat content 